\title{
Pesquisa e produção de conhecimento no campo do Serviço Social
}

\author{
Aldaíza Sposati \\ Pontifícia Universidade Católica de São Paulo (PUCSP)
}

\section{Pesquisa e produção de conhecimento no campo do Serviço Social}

Resumo: Este artigo trata dos caminhos da pesquisa na área do Serviço Social. Parte da polêmica quanto à possibilidade/capacidade do Serviço Social como prática social produzir conhecimentos. Resgata nesse debate a 'guerra das ciências' travada entre físicos e matemáticos com analistas do social, desconsiderando a dimensão científica da pesquisa no âmbito social. Analisa o crescimento da produção científica no Serviço Social através das dissertações e teses dos Programas de Pós-Graduação em Serviço Social, para tanto comenta análises de Iamamoto, Silva e Silva e Carvalho, indica a necessidade da constituição de política de pesquisa a orientar a comunidade epistêmica em Serviço Social, que deve se articular em rede de núcleos de pesquisa

Palavras-chave: pesquisa em Serviço Social, rede de pesquisadores em Serviço Social, produção de conhecimento.

\section{Research and Production of Knowledge in Social Work}

Abstract: This article concerns research paths in the field of Social Work. It begins with the polemic concerning the potential and ability of Social Work as a social practice to produce knowledge. It revives the debate concerning the "war of the sciences" between physicists and mathematicians with social analysts, in which the later do not recognize the scientific dimension of research in the social realm. It analyzes the growth of scientific production in Social Work through dissertations and theses in the Graduate Social Work Program. To do so it comments on the analyses of Iamamoto, Silva and Silva and Carvalho and indicates the need to establish a research policy, orient the epistemic community in Social Work and organize a network of researchers centers.

Key words: research in Social Work, network of researchers in Social Work, production of knowledge. 


\section{Introdução}

O desafio posto pela Revista Katálysis em desencadear na comunidade científica do Serviço Social uma reflexão sobre a produção de conhecimentos na pesquisa em Serviço Social é sem dúvida instigante, e sob diferentes planos.

Em primeiro plano por que esse desafio coloca a pesquisa como objeto do debate deslocando-a, portanto, da condição de meio, método, ferramenta fazendoa alcançar um locus central para estudo. A concepção da pesquisa como mediação constitutiva da identidade e exercício profissional embora correta, tem levado profissionais do Serviço Social a algumas situações-armadilha, das quais destaco:

- a preponderância do debate sobre o método da pesquisa atribuindo caráter secundário ao objeto e aos resultados e à direção social do conhecimento;

- a banalização dos atributos necessários para o desempenho qualitativo na pesquisa, pelo pesquisador, o que termina por construir a falsa relação mecânica entre trabalho do profissional assistente social com a função de pesquisador.

Considero que o debate sobre a pesquisa em Serviço Social é notoriamente significativo para o desmonte dessas 'situações-armadilha' e amplitude do alcance do saber/conhecimento produzido pelo Serviço Social no mundo e na comunidade de pesquisa, e dos pesquisadores.

Um segundo plano, desafiante desse debate sobre a pesquisa em Serviço Social, advém do fato de que, sua enunciação, já parece significar a superação do velho dilema sobre a pertinência em se afirmar que o Serviço Social produz conhecimentos para além de respostas práticas a diversas questões.

Refiro-me tanto ao estatuto secundário dado ao Serviço Social na comunidade científica, que chega, por vezes, a desdenhar da pesquisa em Serviço Social, bem como, ao tradicional embate sobre se o Serviço Social é ciência, técnica, arte, disciplina, etc. e tal.

Como prática social transformada em profissão, pela então 'nova' divisão sociotécnica do trabalho o que ocorreu na Europa e EUA no final do século 19 e no Brasil, pouco antes da metade do século $20-$ o debate sobre a relação entre conhecimento e Serviço Social foi catapultado pelo debate sobre o 'diagnóstico social', enquanto um novo campo de aplicação do conhecimento psicossocial de corte relacional entre sujeito-sociedade ou, mais ao sabor da linguagem a que este conhecimento se filiava, sobre a relação de mútua influência entre indivíduo e meio. Não se tratava de discutir a ciência clássica, enquanto domínio da natureza e suas leis físicas, mas de abrir um novo campo de conhecimento 'abrigado' ou 'ali- nhado' entre os nascentes conhecimentos da Psicologia e da Sociologia.

Tratou-se à partida, como é sabido, da construção do reconhecimento social da identidade dessa prática, que aparecia mais como militância de um grupo da sociedade civil fora da academia do que um campo de produção de conhecimentos. O 'diagnóstico social' como método de análise da relação indivíduo e meio preservava seu assentamento em princípios científicos relativos à personalidade humana e à 'física social'.

Esse corpo de conhecimentos 'sincréticos e ecléticos' dominou por quase três décadas o Serviço Social no Brasil, quando na segunda metade da década de 60 inicia a transmutação da influência européia e americana e desencadeia o processo de reconhecimento de nova identidade social assentada em movimento latino-americano fundado na Teoria Social Crítica, na Economia Política e no confronto político aos autoritarismos dos Estados ditatoriais. Com isto, o Serviço Social constrói novas linhas de força que o identificam com as tensões da dinâmica da sociedade brasileira no período.

O exame crítico das bases ideológicas da constituição sócio-histórica da profissão, e de seus componentes, foi central para a efetiva compreensão de sua inserção nas dimensões ético-valorativas do trato da questão social e de sua função social no processo de reprodução das relações sociais. Esse processo, cuja superação foi de difícil trânsito, confrontou-se com a singularidade dos metodologismos onde predominava a microescala de análise para a ação no real e que levava, em sua logicidade, a superposição do método da pesquisa com o método do diagnóstico social para ação profissional. Se na primeira é a produção do conhecimento que está posta como objetivo/resultado, na segunda é a mudança da situação encontrada a finalidade buscada, embora, é bom que se demarque, em ambas exista uma direção social que orienta o sentido ético da ação profissional. Os procedimentos de analisar para conhecer e analisar para agir exigem diversidade de processos metodológicos, já que supõem resultados diversos.

A sustentação da análise do real na Teoria Social foi se apresentando como caminho essencial para a construção do conhecimento crítico referido à totalidade da sociedade.

Para além destas questões próprias à particularidade do Serviço Social, o desafio proposto contém um terceiro plano, mais geral, para debate. Trata-se do confronto entre a produção da pesquisa social com a pesquisa na área das ciências físicas e matemáticas, demarcado por uma falsa hierarquia entre as nominadas ciências puras e as ciências aplicadas. Nesse contexto, a valoração da física protagonizada por Alan Sokal, físico da Universidade de Nova York, na 'guerra das ciências', categorizou as ciências so- 
ciais como embustes metodológicos, jogos de palavras que através de raciocínios dedutivos forjariam pseudoconhecimentos ou pseudociência.

Seguramente, a natureza social, distinta da natureza física e de seus elementos decodificadores, é sujeitada a múltiplas variáveis demarcadas pelo campo difuso das relações societárias e multiculturais. Todavia, a diversidade das características do objeto (nesse caso de construção sócio-histórica) não lhe retira, em absoluto, sua capacidade de construção da explicação do real. Afinal, o social é sempre uma construção, portanto é grafado pela relação espaçotempo. Todo conhecimento é perene até que um novo conhecimento demonstre sua falência.

Harry Collins, sociólogo das ciências, da Universidade de Cardiff (País de Gales, Reino Unido) conseguiu demonstrar o vácuo dessa 'guerra das ciências' que considera os estudiosos das humanidades incapazes de realizar experimentos, dada sua ausência do conhecimento matemático e, portanto, incapazes de entender e produzir ciência. Collins que vinha analisando a "comunidade de físicos de ondas gravitacionais" através do domínio de conceitos utilizados por essa comunidade, conseguiu interagir com nove físicos dando sugestões e comentários a seus estudos e pesquisas. Mostrou com isto que a especialização interativa permite o diálogo de conceitos o que mostra que pesquisadores de áreas diferentes podem ser tão competentes na análise de um estudo quanto especialistas no ramo (COLLINS, 2006).

É preciso ter claro que a investigação no campo das humanidades é sujeitada a esses confrontos ainda neste terceiro milênio e, principalmente, nas agências de fomento e nos órgãos financiadores da pesquisa.

É com os limites desses três planos e a prática de pesquisadora, que há mais de 25 anos vem se moldando na comunidade de pesquisadores em Serviço Social, bem como, em outras comunidades científicas principalmente as que se dedicam ao exame socioambiental, que as reflexões deste artigo são construídas, destacando algumas polêmicas entre a pesquisa e o Serviço Social e uma contribuição ao debate sobre a 'expertise' do conhecimento do assistente social.

\section{Serviço Social e pesquisa}

A pesquisa torna-se disciplina obrigatória na formação profissional dos assistentes sociais somente em 1982. Embora este fato algumas escolas, departamentos ou faculdades já inseriam em seus currículos a metodologia da pesquisa. Pelo menos esta foi minha experiência ainda na Escola de Serviço Social da PUC-SP na década de 60 do século 20.

É após o processo de reconceituação e, com ele, da construção da identidade social latino-americana do Serviço Social que, ao questionar sua 'base científica' europeu-americana, a preocupação com o conhecimento no ${ }^{1}$ e para o Serviço Social se fortalece. Esse processo tem na implantação de cursos de pósgraduação na década de 1970 uma força ímpar. Primeiro é preciso lembrar que implantar pós-graduação em Serviço Social significou, por si só, a convalidação nos órgãos oficiais do campo do Serviço Social como área de estudo e pesquisa. Aliás, valeria a pena o exame desses documentos inaugurais a fim de resgatar o enunciado desse reconhecimento.

É no âmbito de um curso privado de Serviço Social, na PUC-SP, que tem início a pós-graduação em Serviço Social que vai titular como mestres e doutores um número considerável de docentes das Universidades Públicas brasileiras no campo do Serviço Social.

A produção de teses e dissertações exigia o componente da pesquisa inovadora e, por conseqüência, exigia dos pós-graduados o aprofundamento teórico na metodologia científica, na estatística que passaram a ser disciplinas dos primeiros cursos de mestrado, ainda na década de 70 já que o nível de doutorado só é alcançado na metade da seguinte década.

O reconhecimento institucional pela Coordenação de Aperfeiçoamento de Pessoal de Nível Superior (CAPES) e pelo Conselho Nacional de Desenvolvimento Científico e Tecnológico $(\mathrm{CNPq})$ da área do Serviço Social como campo específico de pesquisa é, certamente, conquista que abriu possibilidade de financiamento da pesquisa em Serviço Social e inclusão de pesquisadores do Serviço Social no quadro geral de pesquisadores do CNPq.

Sem dúvida, esta jovem experiência de três décadas apenas sofre, como as demais áreas das humanidades, certa arrogância das ciências puras face às ciências aplicadas, mas coloca, ao mesmo tempo, questões para os próprios pesquisadores do Serviço Social: teria o Serviço Social efetiva base científica para a produção de conhecimentos com estatuto reconhecido pela academia?

Por certo, ocorreu grande esforço nas décadas de 80 e 90 em fortalecer a base científico-profissional difundida, principalmente, através do processo de desconstrução e reconstrução crítica da profissão e de seu exercício, fundando-se no aporte sócio-histórico da análise do real, que foi disseminado pelo então 'novo' currículo de formação da década de 80 . Esse processo permeou a categoria pela academia, centros de formação, coletivos profissionais, encontros, debates, publicações, congressos. Foi efetivamente a construção da nova cultura crítica no âmbito da profissão e da formação profissional que tem o mérito desse fortalecimento da pesquisa para os assistentes sociais.

O vínculo entre a produção de conhecimento em Serviço Social e o processo sócio-histórico gerou, por sua vez, a capacidade de interlocução entre pesqui- 
sadores provindos do Serviço Social com aqueles ligados a outros saberes. Ampliou-se a inserção e a interlocução interdisciplinar, e com elas, a construção do reconhecimento científico dessa 'nova' perspectiva de análise do real.

Um outro tom de qualidade na produção do conhecimento em Serviço Social procedeu da direção social da prática profissional orientada por um projeto éticocoletivo. Falo da relação de compromisso entre a prática profissional e os interesses das classes populares, subalternas, exploradas. Nessa perspectiva, Carmelita Yazbek (2004) soma com as teses de Boaventura de Sousa Santos (2003) ao afirmar a relação entre conhecimento e hegemonia e situar o campo da produção do conhecimento em Serviço Social sob a orientação de conhecimento contra-hegemônico, porque voltado para as classes subalternas.

No caso, ele não se guia pelas normalidades ou homogeneidades, e sim pelas heterogeneidades, discrepâncias, desigualdades. Adquire o caráter de conhecimento-movimento já que não é um conhecimento conforme, e sim dirigido a um novo lugar/formato de relações e poderes. Nesse sentido é um conhecimento ao mesmo tempo movimento - utopia. Dedica-se a desvendar os invisíveis, os sem-voz, sem-teto, semcidadania. Constitui-se, por tudo isso, em um conhecimento contra-hegemônico.

O enraizamento científico da produção do conhecimento em Serviço Social, orientado pela direção social contra-hegemônica, confere um locus de legitimidade à pesquisa em Serviço Social, embora o processo de legitimidade-legitimação seja contínuo em suas relações externas, interdisciplinares e institucionais.

O reconhecimento da pesquisa no Serviço Social na institucionalidade científica no CNPq como área de conhecimento e na CAPES como área de produção de conhecimentos foi e ainda, de certa forma, o é (quanto a estatuto e a recursos para pesquisa) resultante de inúmeras lutas. Agências de fomento como a paulista Fundação de Amparo à Pesquisa do Estado de São Paulo (FAPESP), a internacional Fundação Ford, entre outras, já incorporam o financiamento de pesquisa no campo do Serviço Social.

Dispõe-se de um coletivo de pesquisa em Serviço Social dentro da ABEPSS (Associação Brasileira de Pesquisa e Ensino em Serviço Social) - cuja sigla ABESS (Associação Brasileira de Escolas de Serviço Social) foi alterada para incluir nesse coletivo a pesquisa, pois antes a ABESS o abrigava sob a nominação de Centro de Documentação e Pesquisa em Políticas Sociais e Serviço Social (CEDEPSS) com reconhecimento pleno, tendo já em seu currículo a realização de doze Encontros Anuais de Pesquisa e Pesquisadores em Serviço Social ocorrendo o último em dezembro de 2006, em Recife.

A Pós-Graduação já conta com duas dezenas de cursos instalados em universidades públicas, filantrópicas e privadas. Esses cursos possuem ativos núcleos de pesquisa com relações internacionais, interdisciplinares, mas que ainda têm frágil inter-relação nacional na medida em que a comunidade científica do Serviço Social não está constituída em rede, o que seria desejável. Vejo aqui um bom novo desafio para a pesquisa no Serviço Social.

É de se relembrar as experiências de intercâmbio internacional que geram pesquisas e estudos comparados entre o Brasil e outras realidades, ressaltase o exemplo da PUC-SP com programas de mestrado e doutorado em Portugal (KARSCH, 2005).

Não se trabalha em rede entre os núcleos de pesquisa das diversas universidades constituindo comunidades de interesse, intercâmbio, acumulação de conhecimentos no âmbito da pesquisa em Serviço Social. Sofremos ainda do isolamento das investigações, quer pela predominância de sua produção vinculada às monografias, dissertações e teses - enquanto trabalhos de caráter individual - quer pela ausência de partilha de objeto e objetivos entre grupos de pesquisadores. É urgente uma Política de Pesquisa em Serviço Social aprovada em coletivos que provoque o elo aglutinador dessa comunidade científica. É de se assinalar a importância de produções interinstitucionais, como algumas iniciativas em desenvolvimento através do Programa de Integração Acadêmica da CAPES (PROCAD), com exemplo inaugural da Universidade Federal do Maranhão (UFMA), PUCSP e Universidade Estadual de Campinas (UNICAMP).

Outra frente é o processo de iniciação científica com alunos da graduação em programas institucionais, como o Programa Institucional de Bolsas de Iniciação Científica (PIBIC) do CNPq, que fortalecem o preparo para a pesquisa no processo de formação do profissional. Pesquisadores em Serviço Social são líderes de grupos de pesquisa com certificação institucional junto ao CNPq.

A área do Serviço Social apresenta em seu conjunto na CAPES 55 linhas de pesquisa ativas, numa relação média aproximada de 10 projetos em andamento para cada uma delas (RELATÓRIO CAPES, 2004). 


\section{Desafios para a pesquisa em Serviço Social}

Marilda Iamamoto (2004) apresentou no XI Encontro de Pesquisadores em Serviço Social um conjunto de desafios postos para a pesquisa a partir da análise que procedeu da produção científica dos Programas de Mestrado e Doutorado em Serviço Social no ano de 2004, a partir do supracitado Relatório CAPES.

Conforme já aludido neste artigo, Iamamoto registra em sua reflexão a ausência - e portanto, a necessidade - de uma "política de pesquisa para a área". Uma política de fomento à investigação sobre os eixos do projeto acadêmico profissional brasileiro. Propõe que os representantes da CAPES, CNPq, Instituto Nacional de Estudos e Pesquisas Educacionais (INEP) e membros do Conselho Federal de Serviço Social (CFESS) e da ABEPSS identifiquem temas prioritários a serem impulsionados no processo de investigação.

Esse quadro referencial de eixos temáticos, adotado pelos centros produtores de estudos e pesquisa, permitiria a agregação de pesquisadores e de resultados de estudos. Do ponto de vista que defendo, permitiria criar comunidades científicas operando em rede, o que facilitaria projetos de intercâmbio nacional, além dos internacionais como já assinalado. A constituição em rede de centros, núcleos, grupos de pesquisa é fundamental para o mútuo conhecimento e intercâmbio de idéias, resultados, questões.

Iamamoto levanta ainda, a ausência de padrões unitários a serem adotados para coleta de dados de núcleos de pesquisa. Alguns registram a pesquisa coletiva dos membros do núcleo de pesquisa e outros, as pesquisas individuais dos alunos que freqüentam o núcleo, provocando várias distorções nos resultados.

Subjaz a esta discussão uma outra 'zona de conflito' quanto à demanda da pesquisa na graduação e na pós-graduação. Quer o docente, quer o aluno da pós-graduação stricto sensu têm que necessariamente apresentar contínua produção científica sob pena de prejudicar a avaliação do curso de pós-graduação perante a CAPES. Nem sempre docentes da graduação e da pós-graduação exercem suas atividades nos dois níveis. Nem sempre a pesquisa é desenvolvida com a mesma intensidade entre os dois níveis. Desta feita, a aplicabilidade dos resultados da pesquisa no processo de formação profissional do assistente social permanece ainda com considerável gap. Dificilmente se faz uma discussão fundamentada pela descoberta da pesquisa ou de uma pesquisa. Ainda sofremos mais o impacto da quantidade das pesquisas do que o impacto do conteúdo, e da qualidade de seus resultados.

Tendo por base o Relatório de Memória da CAPES que identifica 55 linhas de pesquisa dentre os Programas de Pós-graduação em Serviço Social, Iamamoto as agrega em cinco eixos temáticos e discorre sobre as vicissitudes de cada um deles (tabela 1).

Para além dessa análise de Iamamoto (2004), Silva e Carvalho (2005) agregam 719 projetos de pesquisa do período de 2001-2003, agregados no mesmo Relatório CAPES, em 17 eixos temáticos, portanto com maior desagregação temática do que Iamamoto, e concluem que projetos dedicados à infância e à adolescência (88 projetos e $12,23 \%$ do total) são os que concentram maior incidência dentre os 17 eixos temáticos elencados.

Tabela 1 - Agregação das linhas de pesquisa da Pós-Graduação em Serviço Social por eixos temáticos $2001 / 2003$

\begin{tabular}{|c|c|c|c|c|}
\hline \multirow{2}{*}{ Eixos temáticos (1) } & \multicolumn{2}{|c|}{ Linhas de pesquisa } & \multicolumn{2}{|c|}{ Projetos (2) } \\
\hline & N. ${ }^{\circ}$ & $\%$ & $\mathrm{~N}^{\circ}{ }^{\circ}$ & $\%$ \\
\hline Políticas sociais (Estado e Sociedade Civil) & 19 & 34,5 & 238 & 41 \\
\hline $\begin{array}{l}\text { Trabalho (processos, relações com as políticas públicas, } \\
\text { Serviço Social) }\end{array}$ & 8 & 14,5 & 103 & 17,7 \\
\hline Cultura e identidade (processos e práticas sociais) & 8 & 14,5 & 83 & 14,3 \\
\hline $\begin{array}{l}\text { Família (relações de gênero geração, sociabilidade, violên- } \\
\text { cia e cidadania) }\end{array}$ & 6 & 10,9 & 76 & 12 \\
\hline Formação profissional fundamentos e exercícios & 7 & 12,7 & 47 & 8 \\
\hline $\begin{array}{l}\text { Movimentos sociais ( processos organizativos e } \\
\text { mobilização popular) }\end{array}$ & 7 & 12,7 & 34 & 5,5 \\
\hline Total & 55 & 100 & $\mathbf{5 8 0}$ & 100 \\
\hline
\end{tabular}

Fonte: Iamamoto (2004, p. 12-13).

Nota 1: os critérios de agregação das linhas de pesquisas em cinco eixos temáticos são da autora e, segundo ela, sujeitos a debate. Nota 2: inclui projetos concluídos e em andamento. 
Correlacionando as matrizes de eixos temáticos da produção de conhecimentos em Serviço Social elaboradas por Iamamoto e Silva e Carvalho (conforme tabelas 1 e 2), fica claro perceber a priorização de determinadas categorias aglutinadoras, por uma e outra análise, ainda que com algumas coincidências. Todavia, diria que ambas foram organizadas por campos de análise genéricos o que não permite, para além da incidência quantitativa, decodificar qual é efetivamente o objeto de análise na temática ou no grande campo de observação.
A primeira característica apontada para o conhecimento produzido pelo Serviço Social é a "interlocução com o movimento da sociedade". Todavia, a pesquisa em Serviço Social elege alguns dos sujeitos e dos movimentos aos quais se dedica com maior intensidade.

A partir da análise de Iamamoto, considero que se possa entender que o primeiro eixo temático envolve o campo da Política Social, enquanto forças políticas e sociais de seu processo constitutivo. A dinâmica da política social em sua construção, modelo

Tabela 2 - Agregação dos projetos de pesquisa da Pós-Graduação em Serviço Social por eixos temáticos 2001-2003

\begin{tabular}{|c|c|c|}
\hline \multirow[t]{2}{*}{ Eixos temáticos (1) } & \multicolumn{2}{|c|}{ Projetos } \\
\hline & N. & $\%$ \\
\hline Políticas sociais & & \\
\hline Estado e sociedade civil & 56 & 7,78 \\
\hline Saúde & 47 & 6,53 \\
\hline Assistência social & 43 & 5,98 \\
\hline Previdência social & 3 & 0,41 \\
\hline Avaliação de políticas, projetos e progresso & 46 & 6,39 \\
\hline Identidade, cultura e equiiidade & 195 & 27,09 \\
\hline Ética, cultura, direitos humanos & 7 & 0,97 \\
\hline Etnia, gênero, orientação sexual & 55 & 7,64 \\
\hline Cultura, identidade e práticas sociais & 54 & 7,81 \\
\hline Segmentos sociais (ciclo de vida) & 116 & 16,42 \\
\hline Infância, adolescência, juventude, família & 88 & 12,23 \\
\hline Terceira idade, envelhecimento & $\begin{array}{c}21 \\
\mathbf{1 0 9}\end{array}$ & $\begin{array}{c}2,92 \\
15,15\end{array}$ \\
\hline Serviço Social & & \\
\hline Trabalho e prática & 79 & 10,98 \\
\hline Formação profissional & $\begin{array}{c}27 \\
106\end{array}$ & $\begin{array}{c}3,75 \\
\mathbf{1 4 , 7 3}\end{array}$ \\
\hline Trabalho & & \\
\hline Reestruturação produtiva & 82 & $\mathbf{1 1 , 4 0}$ \\
\hline Questão urbana e rural & & \\
\hline Urbana, movimento social, meio ambiente & 42 & 6,67 \\
\hline Agrária, meio ambiente e movimento social & 29 & 4,03 \\
\hline & 71 & 10,7 \\
\hline Outros & 30 & 4,17 \\
\hline Terceiro Setor & 10 & 1,39 \\
\hline
\end{tabular}

Fonte: Silva e Carvalho (2005, p. 97).

Nota 1: Os 17 eixos temáticos, apresentados pelos autores, foram reagregados em 8 preservando a nominação da tabela original nos subtítulos.

Iamamoto reforça a vocação sócio-histórica do Serviço Social em acompanhar o movimento social e, nele, as transformações (às quais eu acresceria as permanências) nas relações entre o Estado e a sociedade. de gestão, implementação de perfil autoritário ou democrático, arena de conflitos, de interesses onde medem forças sujeitos sociais e políticos, centra a preocupação analítica do Serviço Social. Essa dinâ- 
mica de forças e interesses permite tensionar a relação entre a agenda da política e a agenda da justiça social. A política social, campo da prática profissional por excelência, é o locus onde ocorre a constituição de direitos e o reconhecimento da cidadania.

Seguramente, este campo não é exclusivo do assistente social, mas a constituição de direitos, o espaço do sujeito usuário/demandatário é, sem dúvida, um campo em que o conhecimento profissional tem se dedicado. Ressalte-se que se trata do exame preponderante da política social como processo ou movimento do que propriamente os exames de resultados da política, embora já ocorram avanços consideráveis na aplicação de métodos avaliativos de programas, projetos e políticas pela produção do Serviço Social. O aprofundamento da pesquisa sobre os processos profissionais de trabalho do assistente social é ainda tíbio, o que, seguramente, não está facilitando a melhor demarcação do espaço profissional do assistente social no desenvolvimento de cada política social. Este fato tem levado a um amálgama de profissões sociais que se interpenetram identificando-os de modo homogêneo como agentes sociais institucionais das políticas sociais. Pode ser que estejamos realmente sob uma 'nova' divisão sociotécnica de trabalho no campo social como já ocorreu em alguns países europeus.

Iamamoto ressalta que há uma tendência em segmentar os sujeitos sociais a partir de necessidades (crianças, adolescentes, idosos, etc.) o que restringe a visibilidade das demandas/necessidades coletivas de classe, favorecendo focalizações e desconectando-as com as relações sociais que as constituem.

A autora reforça, enfaticamente, a existência de uma relação mimética entre Serviço Social e política social que provoca prejuízo à identidade profissional. O CFESS tem feito críticas reiteradas ao mimetismo entre Serviço Social e Assistência Social. Ainda que correta a perspectiva da distinção entre um e outro, o processo de distinção é por vezes confundido com um processo de distanciamento, e não de diferenciação, o que tem levado alguns mais desavisados a proceder à rejeição da política por si mesma, como se a política de assistência social fosse campo inimigo do Serviço Social ou do assistente social.

Survey desenvolvido pelo IBGE (IBGE, 2006) nas 5.565 cidades brasileiras, identificou que trabalham 12.544 assistentes sociais nas prefeituras, nessa política social, dos cerca de 61 mil assistentes sociais brasileiros. Pouco mais do que um quinto da categoria, está desempenhando sua atividade em âmbito municipal na política de assistência social. Seguramente uma política que envolve um quinto de uma categoria profissional deve ser campo de análise privilegiado para pesquisa, o que não significa identificar o campo do Serviço Social com a Assistência Social.

A respeito das mutações do exercício profissional do assistente social, Jacques Donzelot apresentou em
1998 o artigo A quoi sert le travail social, onde traça um paralelo no exercício profissional no ano de 1972 e, no então, 1998 (DONZELOT; ROMAN, 1998). Em 1972, a questão de fundo colocada para a profissão dizia respeito aos motivos da expansão acelerada da categoria. À época, os profissionais franceses tinham forte desempenho denunciativo sobre as formas de dominação, discriminação, exclusão das classes populares. No caso, exerciam os profissionais forte controle social que possibilitou forte grau de emancipação profissional.

Considera o autor que após vinte e seis anos (19721998) ocorreu a perda de credibilidade na posição 'heróica' do profissional. Essa mutação é justificada tanto pelo desempenho profissional na aplicação dos testes de meios das políticas de enfrentamento da exclusão, como na operação das políticas e programas de transferência de renda; quanto pela escalada de novas profissões sociais em dois novos regimes o de 'inserção' e o 'da cidade'. Essas novas profissões sociais exercem processos de mediação e de mobilização entre pauperizados e instituições, como novas formas de ação social. São 'novas' profissões que produzem a sociedade e não, propriamente, que a vigiam no sentido de denunciá-la o que demonstra um deslocamento da direção social da prática dos assistentes sociais dos anos 1970 para o final do século 20.

Donzelot, para efeito de comparação, nomina a primeira proposta de Serviço Social como clássica e tenta entender quais fatores (históricos, práticos e políticos) levaram a essa mutação. Considera que o novo processo produtivo e o desemprego seqüente geraram um interdito no campo profissional, rebaixando a condição de trabalho/trabalhador à categoria frágil da inserção. Digamos que preponderam respostas paliativas às vítimas da crise, gerando uma nova crise que é a da integração social.

Esse novo processo gerou e gera uma crise das instituições cujos procedimentos e políticas não respondem à nova situação. Por conseqüente, não há mais a anterior demanda do profissional exercer a mediação entre as classes populares e as instituições, mas para realizar a mudança institucional. No lugar da coesão, a vida social passa a ser marcada pela perda/ruptura das regras comuns gerando uma vida social fragmentada.

Donzelot considera que esta mudança gerou um vazio profissional já que os assistentes sociais sabiam trabalhar à margem das instituições, mas não com as instituições. Não se tratava mais de negociar a regra institucional para algumas situações, mas da reinvenção das instituições e das fórmulas de relação entre elas e a população.

Outro fator para o autor é a crise da proteção social que se pode atribuir também às mudanças societárias da família, da mulher, das gerações, além da orientação neoliberal em fragilizar o alcance da proteção. 
O autor põe em questão o conceito dessa ação social. Considera que ao final do século 20 emerge um conceito de ação social que contrapõe profissionais sociais "antigos e modernos". Considera que novos campos da prática social se abrem exigindo do assistente social, por exemplo, o domínio da pedagogia do habitat, só que essa pedagogia não se funda mais na psicologia, mas sim no direito como teoria de vida em sociedade. Outra fonte é a mediação no sentido da recomposição do vínculo social, da restauração de relações entre famílias, habitantes, serviços, face à nova política da cidade e das relações urbanas.

Defende a tese que o conceito de trabalho social está sendo substituído pelo conceito de produção da sociedade. O conceito de trabalho social era fundado na sociedade salarial, na sociedade de produção. A emergência de uma nova concepção surge do fato pelo qual a produção econômica não ser mais suficiente para estruturar a sociedade. A produção da sociedade passa a ser uma nova necessidade objetiva e exige a mobilização de afetos, desejos, aspirações para que a sociedade tenha novos referenciais de identidade e reconhecimento mútuo que espelhem o novo desejo de viver em sociedade e de reconstrução do tecido social.

Algumas 'novas' questões afloram como a relação entre vínculo social e justiça social; a disjuntiva entre socioeconômico e sociopolítico; a proteção social advinda da legislação social do trabalho e advinda dos direitos de cidadania com políticas sociais mais centradas na cidadania e na democracia.

$O$ grande risco que Donzelot salienta é o de que esse novo social seja só uma forma de gestão do "não trabalho" com forte preocupação em legitimar uma gestão social voltada para a construção da "ficção de uma vida democrática" ou a "ilusão de um vínculo" com a sociedade produtiva. No caso, trata-se de forte preocupação como a solução nominada de "terceira via" por Giddens cujo objetivo da ação é fortalecer a integração social pelo mercado cuja aplicação está nas já conhecidas e debatidas políticas do workfare aplicadas pelo governo inglês de Tony Blair.

Outra vertente desse novo momento que inicia o século 21 é a do social, entendido como solidariedade, desconectado da economia e traduzido fortemente no que vem sendo nominado de 'religiosidade civil' praticada por voluntários, organizações não gover- namentais e fundações empresariais. Considera que a renda mínima universal como condição de democracia é um modo de ratificar uma situação onde o assalariado não produz mais suporte à redistribuição de riquezas, o que pode terminar por distinguir uma sociedade de assistidos de uma sociedade de produtores levando ao miserabilismo.

$\mathrm{Na}$ sociedade de mercado é preciso manter a relação emprego com redistribuição social, democracia e justiça social. A proteção social é parte dessa equação e dela não pode ser afastada. Portanto, a direção da ação social como uma questão de justiça social é imprescindível.

Considero extremamente importante esta reflexão de Donzelot ainda que ela já tenha quase dez anos e entendo que contém férteis questões para serem abordadas como eixos temáticos da pesquisa em Serviço Social.

Em 1992 produzi o artigo Serviço Social em tempos de democracia que se ocupa da relação hierárquica entre Serviço Social e Política Social. A construção histórica do Serviço Social registra sua emergência na sociedade civil, e não no Estado. Foi concebido como prática social desenvolvida por agentes de organizações sociais e religiosas já que a perspectiva da estatização do social era entendida como manifestação de adesão à ideologia totalitária e comunista. Andrew Vicent, professor inglês, desenvolve preciosa análise histórica sobre como as idéias de Beveridge quanto à provisão pública do social, incidem de forma conflituosa na Charity Organisation Society (COS), berço do Serviço Social, sendo criticadas (VICENT, 1999).

A exceção da legislação social do trabalho e, principalmente, do seguro social, é a partir da institucionalização do nominado welfare state que as políticas sociais são estabelecidas como de responsabilidade estatal e direito de cidadania de todos. Este fato significou que a provisão social deslocou-se da sociedade civil, berço do Serviço Social, para o Estado, ocasionando nessa transmutação uma subordinação do Serviço Social enquanto campo de uma dada prática fosse concretizado pelo exercício da profissão e do profissional assistente social como agente institucional do Estado.

Essa passagem do campo privado para o estatal, no âmbito do Serviço Social brasileiro, veio mesclada com a luta contra o Estado autoritário e ditatorial, gerando contínua desconfiança das políticas públicas e, desta feita, subordinando o alcance dos direitos 
sociais a essa desconfiança e, mesmo, a uma desconfiança com a ação profissional do assistente social, exercida no interior do Estado como um feitor da dominação burguesa.

No atual currículo ou no processo de formação profissional, a política social é apresentada como disciplina à parte sem uma clara decodificação de seus processos internos como campo da ação profissional.

Ressalto esses aspectos, ainda que de passagem, já que são explorados a detalhes no artigo citado, por entender ser necessário mergulhar mais a fundo nas implicações e dinâmicas das políticas sociais como campo primordial da produção de conhecimentos pelo Serviço Social.

Em defesa de constituirmos temáticas de comunidades científicas operando em rede no Serviço Social é que procedi a toda esta digressão, pois considero que os eixos temáticos para pesquisa que vêm sendo utilizados encapam a visibilidade de questões que nos devem ser caras, para a construção do conhecimento no Serviço Social, a partir de seu ponto de vista, ou melhor, do topos da produção desse conhecimento. Nesse sentido, incluo aqui a reflexão da pesquisadora finlandesa Kati Narhi (2002) sobre a expertise da produção do conhecimento no Serviço Social.

\section{A expertise do conhecimento em Serviço Social}

Embora este artigo se ocupe em desenvolver uma discussão sobre a particularidade do conhecimento em Serviço Social, é notório que o campo de estudo do Serviço Social situa-se dentre as manifestações da questão social e nelas, das relações entre os sujeitos Estado-Sociedade-Mercado, em toda sua complexidade constitutiva, e, como assinalado, na perspectiva da construção de um conhecimento contrahegemônico, isto é, cuja direção social busque descrever, sistematizar, explicar o modo de vida, de viver, de luta, de organizar, de representar, de manifestar das classes populares e das situações que vivenciam perante a justiça social, a democracia e o trabalho neste terceiro milênio.

Todo o conhecimento é produzido a partir de um topos, de um dado modo de ver e de olhar. Entendese aqui que o conhecimento em Serviço Social revela a leitura do objeto a partir de um determinado modo de ver. Todo o ponto de vista não deixa de ser a vista a partir de um ponto. Isto não significa propugnar pela uniformidade das análises, saberes ou conhecimentos produzidos no campo do Serviço Social, mas reconhecer que esse modo de ver específico indica uma tendência que pode se constituir na expertise do conhecimento em Serviço Social. Em outras palavras, a autora tenta construir elementos para responder a questão: "o que a formação em Serviço Social habilita para captar e interpretar como determinados elementos do real?". Essa busca não significa que a formação básica em outras áreas profissionais não possa ter similitude com a busca do Serviço Social, bem como não significa que pesquisadores com formação básica em Serviço Social não possam alcançar outras comunidades científicas.

Para desenvolver esta reflexão vou me pautar no artigo de Kati Narhi: Transferable and Negotiated Knowledge: Constructing Social Work Expertise for the Future (Conhecimento transmissível e negociável: construindo uma expertise para o Serviço Social no futuro (NARHI, 2002).

Kati Narhi desenvolve seu trabalho de pesquisa na Universidade de Jyaskyla da Finlândia. Por três anos trabalhou nessa pesquisa que procura explorar, a partir das descrições dos próprios profissionais, o conhecimento e expertise profissional sobre a marginalização espacial. A pesquisadora estudou os esforços de vinte assistentes sociais no combate da exclusão social em áreas residenciais finlandesas a partir de conteúdos transmitidos, por eles mesmos, em encontros regulares, onde falavam sobre seu conhecimento sobre a relação entre: o meio ambiente local, o bem-estar humano e a relação exclusão/inclusão social que a autora define, em síntese, como expressão da marginalização espacial ou da segregação urbana. Discutiram, no desenvolvimento do estudo, textos sobre pesquisa a fim de que a pesquisadora pudesse captar, com maior fidedignidade, o topos ou o modo de ver e pensar dos assistentes sociais.

Kati Narhi partiu da hipótese de que o exercício da profissão é político e está plenamente definido como tal. Assim, o tipo de conhecimento de assistentes sociais sobre suas observações busca alcançar novos e consistentes elementos para futura comunicação com outros atores com o objetivo de influenciar e resolver questões concernentes ao fenômeno estudado (conhecimento como movimento ou mediação).

Desse ponto de vista a linguagem no conhecimento em Serviço Social tem lugar central como expressão da realidade construída por, e entre, assistentes sociais.

Outra grande característica levantada pela autora diz respeito ao papel da experiência para o conhecimento em Serviço Social, o que traz forte correlação com o conhecimento prático em suas várias formas. $\mathrm{O}$ profissional parte de experiências de usuários e exemplos de casos em sua lógica de construção do conhecimento.

Narhi considera que é preciso distinguir vários tipos de conhecimento para poder captar características de uma expertise. Distingue o conhecimento derivado da pesquisa empírica, o conhecimento teórico, o conhecimento pessoal, o processual e o prático. O conhecimento sobre o fenômeno é o conhecimento substancial, e o conhecimento sobre a forma de usar esse conhecimento seria, por decorrência, a expertise. 
O conhecimento teórico é aquele dedicado às definições e o prático é o conhecimento do fazer, o conhecimento técnico do 'saber como', ou sobre o usuário. O conhecimento empírico é aquele baseado em fatos, e a base empírica do conhecimento para os assistentes sociais reside na coleta das experiências de seus usuários. Portanto, inter-relacionar experiências e exemplos de situações da prática de usuários de serviços é um meio para produzir conhecimento sobre a vida pessoal, as dificuldades e situações de vida desses mesmos usuários. Assim, o conhecimento produzido termina sendo fortemente marcado pelo conhecimento prático, o que não significa desconhecer ou isolar-se de teorias gerais, mas construir um campo de conhecimento fortemente demarcado pela experiência real de vida, de dadas situações, por segmentos e classes sociais.

O conhecimento prático embora de orientação situacional, experimental, pessoal ou social, tem dentro de si uma orientação teórica. A questão é a de fazer saltar esse conhecimento para o plano dos conceitos, a fim de obter novo grau de generalização ou explicação que não seja tão só afeto a uma prática isolada ou a de um grupo. O acúmulo de informação precisa ser processado por pesquisadores capazes de captar nuances e sistematizá-las.

Não se trata aqui de valorizar o chamado conhecimento instrumental para a solução de problemas numa perspectiva da racionalidade técnica de profissões práticas, mas sim de alcançar um conhecimento que preserve as dimensões socioculturais e históricas e permita ter sua consolidação não como padrão ou homogeneidade, mas, exatamente ao contrário, sobre suas diversidades nas quais residem as potências de mutação.

A perspectiva de uma direção social a permear o Serviço Social confere a precedência de valores na construção do conhecimento, como já dito, ele tem uma perspectiva intencional. Já olha um fenômeno em uma dada direção que é a de como superar algo que está posto como negatividade, vitimização, opressão, exclusão, etc.

A perspectiva do acúmulo do conhecimento traz tanto a perspectiva do partilhamento como a de transmissibilidade desse conhecimento. Isto é, ele implica a capacidade de construir novos sentidos contextuais. Este processo abre o campo de registro de singularidades contextuais que podem advir de aspectos culturais e nele de tradições, mitos, superstições, etc. talvez até mesmo de uma aproximação com o campo antropológico.

Kati Narhi busca com sua pesquisa responder a questões: Qual o tipo de conhecimento? Qual a base do conhecimento? Quais as formas de saber? O que, enfim, uma possível expertise do Serviço Social poderia incorporar como conhecimento de, e sobre a sociedade contemporânea. Para responder a essas ques- tões, Narhi relembra que o conhecimento e o sujeito do conhecimento não estão dissociados, portanto, a realidade alcançada é um contexto-relação onde o conhecimento é um fenômeno socialmente construído.

Considera a autora, um reforço ao que aqui já foi registrado, que o conhecimento produzido por assistentes sociais tende a ser um conhecimento prático sob várias formas - de caráter processual e que se desencadeia a partir da experiência, portanto na relação do profissional com a situação concreta de vida observada e relatada pelos usuários. Trata-se de experiências interativas com centralidade na linguagem, sendo sempre um conhecimento partilhado.

Narhi entende que a "singularidade" do Serviço Social é derivada do modo como são enfrentadas questões relacionadas ao bem-estar, como respostas à questão social. Busca entender necessidades e processos informais através do qual são realizadas negociações. Acentua que o conhecimento que serve à prática requer compromisso com a situação concreta de vida dos usuários de serviços.

\section{Notas conclusivas}

O percurso desta reflexão pelo seu caráter de ensaio não permite propriamente conclusões e sim indicações quanto à produção de conhecimentos no campo do Serviço Social.

Para além das análises gerais da sociedade o Serviço Social, pela sua inserção concreta no real, constrói uma rica contribuição para a Teoria Social.

Entendo que já temos maturidade para melhor explicitar 'eixos temáticos' com mais precisão, de modo a orientar e dar rumos mais concretos para a pesquisa em Serviço Social. Diversamente das 'novas' modalidades de agentes sociais, ou mesmo de maior inserção social de psicólogos e pedagogos, dentre outras profissões de recente compromisso com os desafios postos para as classes subalternas, os assistentes sociais têm forte e longa trajetória nesse saber-compromisso sobre as relações sociais.

Considero que o esforço a ser empreendido é o de interconectar pesquisadores do Serviço Social, construindo redes que levem a consolidar o estatuto profissional de uma comunidade científica própria.

Nesse sentido esta reflexão é, ao mesmo tempo, um pensamento e uma provocação à contínua luta de consolidação de uma profissão nos diferentes campos de exercício, neles inclusa a sua dedicação a produção científica.

\section{Referências}

ABESS. A produção do conhecimento e o Serviço Social. Cadernos ABESS n. 5, São Paulo: Cortez, maio 1992. 
Produção Científica e Formação Profissional. Cadernos ABESS n. 6. São Paulo: Cortez, set. 1993.

BAPTISTA, M. V. A investigação em Serviço Social. São Paulo: Veras Edit., 2006.

COLLINS, H. Comunidade de físicos. Folha de São Paulo, São Paulo, 08 jul. 2006. Caderno Ciência.

DONZELOT, J.; ROMAN, J. A quoi sert le travail social. Revista Esprit, Paris, n. 211, mar./abr. 1998.

IAMAMOTO, M. V. Os caminhos da pesquisa em Serviço Social. In: XI ENCONTRO NACIONAL DE PESQUISADORES EM SERVIÇO SOCIAL, ABEPSS, Fortaleza. Anais... Fortaleza: ABEPSS, 2004.

IBGE - Instituto Brasileiro de Geografia e Estatística. Perfil dos Municípios Brasileiros. Assistência Social. Rio de Janeiro: IBGE/MDS/MPOG, 2006.

KARSCH, U. (Org.). Estudos do Serviço Social Brasil e Portugal II. São Paulo: EDUC, PUCSP, 2005.

NARHI, K. Transferable and Negotiated Knowledge: Constructing Social Work Expertise for the Future. Journal of Social Work, Londres: SAGE Editora, v. 2, n. 3, dez. 2002.

RELATÓRIO CAPES. Linha de Pesquisa Memória da PósGraduação, Sistema de Avaliação, Relações Nominais. Brasília, 30 abr. 2004.

RODRIGUES, M. L.; LIMENA, M. M. (Org.) Metodologias multidimensionais em Ciências Humanas. Brasília: LiberLivro Editora, 2006. v. 1.

SANTOS, B. de S. O papel da produção de conhecimento na transformação social. In: SEMINÁRIO INTERNACIONAL 'O PAPELDASOCIEDADE CIVIL NAS NOVAS PAUTAS POLÍTICAS’. São Paulo: ABONG, set. 2003.

SILVA, M. O. da S.; CARVALHO, D. B. B. (Org.). Serviço Social, pós-graduação e produção de conhecimento no Brasil. São Paulo: Cortez, 2005.

SPOSATI, A. Carta-Tema: a assistência social no Brasil 1983-1990. São Paulo: Cortez, 1991.

Serviço Social em tempos de democracia. Serviço Social \& Sociedade, São Paulo: Cortez, n. 39, p. 5-30, ago. 1992.

Movimentos utópicos da contemporaneidade: diálogo com Boaventura de Sousa Santos. Educação, Sociedade e Cultura, Porto, n. 16, p. 5-43, 2001.
VICENT, A. W. The Poor Law Reports of 1909 and the Social Theory of the Charity Organisation Society. In: GLADSTONE, D. (Org.). Before Beveridge Welfare Before the Welfare State. IEA Health and Welfare Unit. Choice Welfare, n. 47, p. 64-85, London, 1999.

YAZBEK, C. Os caminhos para a pesquisa no Serviço Social. In: IX ENPESS - ENCONTRO NACIONAL DE PESQUISADORES EM SERVIÇO SOCIAL, ABEPSS, 2004. Conferência.

\section{Nota}

1 Ver a respeito: CadernoABESS n. 5(ABESS, 1992), Caderno ABESSn.6(ABESS, 1993)e Baptista(2006).

\author{
Aldaíza Sposati \\ Doutora em Serviço Social pela PUCSP \\ Pós-Doutorada pela Faculdade de Economia de \\ Coimbra - Portugal \\ Professora titular da PUCSP do Programa de Pós- \\ Graduação em Serviço Social \\ Coordenadora do Núcleo de Estudos e Pesquisas em \\ Seguridade e Assistência Social (NEPSAS) \\ Coordenadora do Centro de Estudos das Desigual- \\ dades Socioterritoriais (CEDEST) \\ Rua João Ramalho, 182, sala 605, 6. andar \\ Perdizes \\ São Paulo - São Paulo \\ CEP: 05015-901
}

